\title{
Cortisol Levels and Risk for Psychosis: Initial Findings from the North American Prodrome Longitudinal Study
}

\author{
Dr. Elaine F. Walker, Ph.D.,
}

\begin{abstract}
(C) 2013 Society of Biological Psychiatry. Published by Elsevier Inc. All rights reserved.
Correspondence: Elaine F. Walker, PhD, Department of Psychology, 36 Eagle Row, Emory University, Atlanta, GA 30322 (psyefw@emory.edu).

Department of Psychiatry, Harvard Medical School at Beth Israel Deaconess Medical Center (Drs Seidman and Tsuang) and Massachusetts General Hospital, Boston (Drs Seidman and Tsuang); Department of Psychiatry, University of Calgary, Calgary, Alberta, Canada (Dr Addington); Department of Psychiatry, University of California, San Diego (Drs Cadenhead, Tsuang, and Heaton); Departments of Psychology and Psychiatry and Biobehavioral Sciences, University of California, Los Angeles (Dr. Cannon); Department of Psychiatry, Yale University, NewHaven, Connecticut (Drs McGlashan, Woods); Department of Psychiatry, University of North Carolina, Chapel Hill (Dr Perkins); Department of Psychology, Emory University, Atlanta, Georgia (Drs. Trotman, Walker); Center for Translational Neuroscience, and Computational and Life Sciences, Emory University (Dr. Pearce); Schizophrenia Spectrum Research Program, Division of Adult Translational Research, National Institute of Mental Health, Bethesda, Maryland (Dr Heinssen); and Department of Psychiatry, Zucker Hillside Hospital, Long Island, New York (Dr Cornblatt).
\end{abstract}

Financial Disclosures.

Dr. Addington has received investigator-initiated research funding support from multiple not-forprofit entities including the National Institute of Mental Health, Ontario Mental Health Foundation, and the Schizophrenia Society of Ontario. Dr Addington has served as a consultant for Pfizer, AstraZeneca Pharmaceuticals, and Janssen Pharmaceuticals. Dr. Cadenhead has received investigator-initiated research funding support from the National Institute of Mental Health and has no biomedical financial interests or potential conflicts of interests to report. Dr. Cannon has received investigator-initiated research funding support from multiple not-forprofit entities including the National Institute of Mental Health, NARSAD, and the Staglin Music Festival for Mental Health. Dr Cannon has served as a consultant for Janssen Pharmaceuticals and Eli Lilly and Company. Dr. Cornblatt has received investigator-initiated research funding support from not-for-profit entities including the National Institute of Mental Health and the Stanley Medical Research Institute. She has also served as a consultant for Eli Lilly and Company, Bristol-Myers Squibb, and Janssen Pharmaceuticals and has received unrestricted educational grants from Janssen Pharmaceuticals. Dr. Cornblatt has also served as a consultant for Hoffman La Roche. Dr. Heinssen is an employee of the nonprofit National Institutes of Health and reports no biomedical financial interests or potential conflicts of interest. Dr. Mathalon has received investigator-initiated research funding support from not-for-profit entities including the National Institute of Mental Health. He has served as a scientific consultant to Bristol Myers Squibb. Dr. McGlashan has received investigator- initiated research funding support from the National Institute of Mental Health, the Personality Disorder Research Foundation, and Eli Lilly and Company. Dr McGlashan has served as a consultant for Eli Lilly and Company, Pfizer, Solvay/Wyeth, and Roche Pharmaceuticals. Dr. Pearce reports no biomedical financial interests or potential conflicts of interest Dr. Perkins has received investigator-initiated research funding support from not-for profit entities including the National Institute of Mental Health and The San Francisco Foundation. In the past Dr Perkins received research funding from AstraZeneca Pharmaceuticals, Bristol-Myers Squibb, Otsuka Pharmaceutical Co Ltd, Eli Lilly and Company, Janssen Pharmaceuticals, and Pfizer and consulting and educational fees from Dainippon Sumitomo Pharma, AstraZeneca Pharmaceuticals, Bristol-Myers Squibb, Eli Lilly and Company, Janssen Pharmaceuticals, GlaxoSmithKline, Forest Labs, Pfizer, and Shire. Dr. Seidman has received investigator initiated research funding support from multiple not-for profit entities including the National Institute of Mental Health, the National Institute on Aging, the Commonwealth of Massachusetts Department of Mental Health, the National Alliance for Research on Schizophrenia and Depression (NARSAD), and the Sidney R. Baer Jr. Foundation. He has not received funding from for-profit entities in the past 12 months. In the past he received unrestricted educational support from Janssen Pharmaceuticals and has served as a consultant for Shire. Dr. Tsuang has received investigator-initiated research funding support from multiple not-for-profit entities including the National Institute of Mental Health and has received research grants from Janssen Pharmaceuticals. Dr. Trotman reports no biomedical financial interests or potential conflicts of interest. Dr. Walker has received investigator-initiated research funding support from not-for-profit entities including the National Institute of Mental Health and NARSAD and reports no biomedical financial interests or potential conflicts of interest. Dr. Woods has received investigator-initiated research funding support from multiple not-for-profit entities including the National Institute of Mental Health, the Donaghue and Stanley foundations, and NARSAD. In adadition, he has received investigator-initiated research funding support from multiple for-profit entities including UCB Pharma and Bristol-Myers Squibb and has consulted for Otsuka and Schering-Plough. Dr Woods has not served on speaker's bureaus. Disclaimer: The views expressed are those of the authors and do not necessarily reflect the official views of the National Institute of Mental Health, the National Institutes of Health, or any other branch of the US Department of Health and Human Services.

Publisher's Disclaimer: This is a PDF file of an unedited manuscript that has been accepted for publication. As a service to our customers we are providing this early version of the manuscript. The manuscript will undergo copyediting, typesetting, and review of the resulting proof before it is published in its final citable form. Please note that during the production process errors may be discovered which could affect the content, and all legal disclaimers that apply to the journal pertain. 
Emory University, Atlanta, GA

Dr. Hanan Trotman, Ph.D.,

Emory University, Atlanta, GA

Dr. Brad D. Pearce, Ph.D,

Emory University, Atlanta, GA

Dr. Jean Addington, Ph.D., University of Calgary, Calgary, Alberta, Canada

Dr. Kristin S. Cadenhead, MD., University of California, San Diego, CA

Dr. Barbara A. Cornblatt, Ph.D.,

Zucker Hillside Hospital, New York, NY

Dr. Robert Heinssen, Ph.D.,

National Institute of Mental Health, Bethesda, MD

Dan H. Mathalon, MD., Ph.D.,

University of California, San Francisco, CA

Dr. Diana O. Perkins, MD,

University of North Carolina, Chapel Hill, NC

Dr. Larry J. Seidman, Ph.D.,

Harvard University, Boston, MA

Dr. Ming T. Tsuang, MD,

University of California, Irvine, CA

Dr. Tyrone D. Cannon, Ph.D.,

Yale University, New Haven CT

Dr. Thomas H. McGlashan, MD., and

Yale University, New Haven CT

Dr. Scott W. Woods, MD.

Yale University, New Haven CT

\section{Abstract}

Background-Studies of biomarkers of hypothalamic-pituitary-adrenal (HPA) activity indicate that psychotic disorders are associated with elevated cortisol. This study examined cortisol levels in healthy controls and individuals who meet clinical high risk (CHR) criteria for psychosis. It was hypothesized that cortisol levels would be; a) elevated in the CHR group relative to controls, b) positively correlated with symptom severity, and c) most elevated in CHR patients who transition to psychotic level severity.

Methods-Baseline assessments were conducted at eight centers in the North American Prodrome Longitudinal Study (NAPLS). The present CHR sample included 256 individuals meeting Structured Interview for Prodromal Syndromes (SIPS) criteria, and 141 controls, all of whom underwent baseline assessment and measurement of salivary cortisol.

Results-Consistent with previous reports, there was an effect of age on cortisol, with increases through the adolescent/early adult years. Analysis of covariance (ANCOVA) showed a main effect of diagnostic group, with the CHR group showing higher cortisol. There were modest, positive correlations of cortisol with baseline symptom severity, and ANCOVA revealed higher baseline 
cortisol in those who transitioned to psychotic level symptoms when compared to healthy controls and CHR subjects who remitted.

Conclusions-The present findings add to accumulating evidence of heightened cortisol secretion in CHR individuals. The findings also indicate nonspecific associations between cortisol levels and symptom severity, as well as symptom progression. The role of HPA activity in prediction of conversion to psychosis, and its relation with other biomarkers of risk, should receive attention in future research.

\section{Keywords}

psychosis; prodrome; high-risk; stress; cortisol; longitudinal

\section{Introduction}

The role of stress hormones in triggering the expression of vulnerability to mental disorder has become a significant focus of research.(1) The importance of this area of investigation has been highlighted by advances in our understanding of neurohormonal signaling, epigenetic processes, and gene-environment interactions in the etiology of mental disorders.

Within the last decade, a substantial body of literature has accumulated on hypothalamicpituitary-adrenal (HPA) function in schizophrenia and other psychoses, and a 2008 review of the results supports five general conclusions (1): 1) Indices of HPA activity (cortisol and adrenocorticotropic hormone $[\mathrm{ACTH}]$ ) are elevated in some patients with schizophrenia and other psychoses, especially in nonmedicated and first-episode patients; 2) antipsychotic medications typically reduce cortisol, with more pronounced reductions in drug responders; 3 ) drugs that augment dopamine (DA) or exacerbate/induce psychotic symptoms also increase HPA activity; 4) glucocorticoid receptors appear to be down-regulated in psychotic patients, suggesting reduced negative feedback on the HPA axis, and 5) reduced hippocampal volume, a correlate of hypercortisolemia, is among the most consistently reported brain abnormalities in psychotic patients.

Reports published subsequent to the above review have yielded similar findings (2-8). For example, research has shown elevated cortisol in first episode and recent onset psychotic patients (3-4), and increased activity of systemic cortisol metabolism in schizophrenia patients (5). Among mood disorders patients, those with psychotic symptoms manifest greater elevations in cortisol (6). Further, heightened cortisol levels (7) and more pronounced cortisol reactivity to daily stress (8) have been observed in relatives of psychotic patients. Recently, a study of first-episode psychotic patients revealed no differences from controls in cortisol, but the magnitude of the decrease in cortisol over 12 weeks was associated with the decline in severity of psychotic, negative, and mood symptoms (9). Consistent with this, cortisol levels are correlated with severity ratings of a range of symptoms in psychotic patients (10).

Because many view the prodromal phase as affording the greatest opportunities for preventive intervention, individuals who manifest clinical signs of psychosis risk (Clinical High Risk - CHR) have become the focus of research interest. Structured measures for prospective assessment of the prodrome have been developed (11-12), and individuals who meet criteria using these measures are shown to have a significantly elevated rate of conversion to psychosis; $20 \%$ to $40 \%$ of these individuals subsequently develop a psychotic disorder (11-13). Further, CHR subjects manifest brain abnormalities similar to those detected in first-episode patients; namely reduced gray matter volume and white matter abnormalities (15-18). 
Indices of the biological response to stress are of particular interest during the prodromal phase, given that stress is assumed to play a role in triggering symptoms. To date, only a few published reports have explored the HPA system, or its activity, in a CHR or 'prodromal' sample (19). In one study, pituitary volume was measured via magnetic resonance imaging in a CHR group (20). The subjects who later developed psychosis had a significantly larger baseline pituitary volume compared with those who did not. The authors suggested that the larger pituitary volume may be indicative of heightened HPA activation (20). However, in another report on 18 CHR subjects, this same research group found that cortisol showed no significant relationship with global psychopathology, psychotic symptoms, or pituitary and hippocampal volumes, but was positively correlated with ratings of depression and anxiety (21). These investigators also conducted a study in which they administered the dexamethasone corticotrophin releasing hormone (DEX/CRH) test to twelve CHR subjects at baseline (22). Three of the twelve developed psychosis within 2 years. Given the small sample size, statistical analyses were not conducted, but the authors reported that participants who did not develop psychosis showed a trend toward higher cortisol levels at the latter stages of the test, when compared to the three participants who did develop psychosis.

Other studies with larger samples have indicated that CHR subjects do manifest higher cortisol levels (23-25). A recent report indicates that CHR youth who go on to develop a psychotic disorder show significantly higher cortisol levels in the year preceding onset (24). The study included 56 CHR youth, with 14 subsequently converting to a psychotic disorder. Multiple saliva samples were obtained to enhance cortisol estimation reliability. As in previous studies of HPA activity in adolescence, an age-related increase in cortisol secretion was also observed, suggesting that the developmental period of peak risk for prodromal onset is also characterized by greater stress sensitivity. Other research on CHR samples has shown an association between cortisol and severity of positive and nonspecific symptoms (2, 19). Finally, a novel study of CHR and psychotic patients measured stress-induced cortisol and DA release, using PET to index percent change in receptor binding between conditions (stress versus control) in the limbic, associative, and sensorimotor striatum (25). The stressor was a challenging mental arithmetic task. Compared to healthy controls, CHR and psychotic patients had more pronounced DA response in the associative and sensorimotor striatum, as well as a greater cortisol response to the stressor. Further, there was a significant association between the increases in cortisol and DA.

With increasing evidence that neurohormones play a role in neuronal function and epigenetic processes, the importance of research on HPA activity in CHR samples has become more apparent (26). To date, the research in this area has often utilized nonoptimal measurement procedures (e g., single assays without controlling for diurnal changes) and has involved small samples that vary in demographics. The present study extends this line of investigation in a larger sample of CHR individuals participating in the North American Prodrome Longitudinal Study (NAPLS). It is hypothesized that the CHR group will show significantly higher cortisol levels than healthy controls, and that cortisol levels will be positively correlated with ratings of symptom severity and with the progression of positive prodromal symptoms.

\section{Methods and Materials}

\section{Sample}

The NAPLS prospective study of prodromal syndromes is an ongoing, collaborative longitudinal project (27). The objectives are to enhance prediction of psychosis in clinicallydefined high-risk individuals and shed light on the neural mechanisms subserving conversion. At the half-way mark of baseline data collection, with a sample of 540 (360 
CHR and 180 controls), there is adequate power to conduct data analyses aimed at addressing key hypotheses. The second half of the baseline sample will provide the opportunity for replication analyses.

The present investigation includes those participants, of the 540 assessed at baseline, for whom dietary information and saliva for assay were obtained, and the samples were adequate for assay. These data were available for 397 participants; 256 CHR subjects (146 males, 110 females) who met prodromal syndrome criteria and 141 (76 males, 65 females) healthy controls. This subsample comprises all participants in the NAPLS project, as of the study midpoint, for whom at least one saliva sample for baseline cortisol assay was available (27). The age range of all participants was 12 to 35 years with a mean age of 19 ( $\mathrm{SD}=4.2)$ for the CHR group and $19.1(\mathrm{SD}=4.6)$ for the control group.

The protocol was approved by Institutional Review Boards at all NAPLS sites where data were collected (Emory University, Harvard University, University of Calgary, University of California Los Angeles (UCLA), University of California San Diego (UCSD), University of North Carolina (UNC), Yale University, and Zucker Hillside Hospital), and all participants provided informed consent or assent (and parental informed consent) for minors.

\section{ASSESSMENT PROCEDURES AND MEASURES}

Participants were screened using the Structured Interview for Prodromal Syndromes (SIPS) (11) at initial assessment and follow-ups. The SIPS contains the Scale of Prodromal Symptoms (SOPS) which rates the severity of symptoms with the following scale: $0=$ absent, 1 = questionably present, $2=$ mild, $3=$ moderate, $4=$ moderately severe, $5=$ severe but not psychotic, and $6=$ very severe and psychotic. The rated symptoms comprise four domains; positive (e.g., unusual thoughts or ideas, suspiciousness, perceptual abnormalities, disorganized communication), negative (e.g., social isolation, avolition, decreased expression of emotion, decreased ideational richness, deteriorated role function), disorganized (e.g., odd behavior, bizarre thinking, trouble with focus and attention), and general (sleep disturbance, dysphoric mood, impaired stress tolerance, and motor disturbances). Following SIPS procedures, subjects were designated as prodromal if they met one or more of four sets of criteria; 1) Brief Intermittent Psychotic Syndrome (BIPS) if rated a 6 on one positive symptom in the past 3 months, Attenuated Positive Symptom (APS) syndrome if rated a 3, 4, or 5 on at least one positive symptom, 3) Genetic Risk and Deterioration Syndrome (GRDS) in a person with a first degree relative with a nonaffective psychotic disorder who shows a steep functional decline over the past year, or 4) meeting criteria for Schizotypal Personality disorder (SPD) at the age of 18 or under. Individuals in the CHR group can meet criteria for more than one prodromal syndrome. Among the sample of 256 CHR participants in the present study, $89 \%$ met criteria for APS, $18 \%$ met criteria for GRD, $14 \%$ met criteria for SPD, and 3\% met criteria for BIPS.

The Structured Clinical Interview for Axis I $D S M-I V$ Disorders (28) was administered to diagnose Axis I disorders at the initial and annual follow-up assessments. The SCID-I/P was utilized to maintain consistency in the diagnostic procedure across participants and over time as they entered young adulthood through the longitudinal course of the study.

A detailed description of the study procedures is presented in detail elsewhere (27). In brief, CHR participants were excluded if they had ever met DSM-IV criteria for an Axis I psychotic disorder. Control participants were excluded if they met criteria for an Axis I psychotic disorder, had a first-degree relative with a current or past psychotic disorder, or met prodromal criteria. General exclusions included substance dependence, neurological disorder, or Full Scale IQ <70. 
Assessments were conducted by trained interviewers who met reliability standards for the project (27). Interviewers were clinical psychologists, psychiatrists, and other mental health staff. Cross-site reliability in symptom ratings was established prior to study initiation and on a yearly basis. The kappa statistic was used to compare trainee agreement with the "gold standard" diagnosis on the SOPS ratings. Within all sites, intra-class correlations for the symptom ratings exceeded .80 , thus were high.

\section{SALIVA COLLECTION AND ASSAY}

Participants were provided with dietary instructions to observe the evening before and the morning of sampling. These included refraining from caffeine, alcohol, dairy products, and nonprescription medications. They were queried to confirm compliance with these instructions.

Saliva samples for cortisol assay were obtained three times during baseline assessment in the research clinic, prompted by a timer to be approximately on the hour (i e, over two hours), beginning on average about 10:00 a.m., with a range from 9:00 to 11:30 a.m. at onset of sampling ( $\mathrm{SD}=26$ minutes), and no difference between the groups in time of sampling onset, $\mathrm{t}(1,396)=1.39, \mathrm{p}=.17)$. Multiple saliva samples $(n=3)$ were obtained to derive an average and increase the reliability of the cortisol estimate (29).

Saliva was stored in a $-20^{\circ} \mathrm{C}$ freezer. In preparation for assay, samples are rapidly thawed and centrifuged. All samples are assayed for salivary cortisol (ug/dl) using a highly sensitive enzyme immunoassay (Salimetrics, State College, PA). The test uses about 25 micro liter of saliva (for singlet determinations), has a range of sensitivity from 0.007 to $1.8 \mathrm{mg} / \mathrm{dl}$, and average intra- and interassay coefficients of variation of less than $10 \%$ and $15 \%$. All samples are assayed in duplicate.

\section{DATA ANALYSES}

Statistical analyses were conducted with PASW statistics 18 (SPSS Inc, Chicago, Illinois) statistical software. Independent sample t-tests or chi-square tests were used to compare the CHR and control groups on demographic and clinical characteristics, and analyses of covariance (ANCOVA) was used to test group differences in cortisol. Correlational analyses were conducted to examine the relation of cortisol levels with symptom ratings.

For purposes of normalizing the distribution of age for analysis, the sample was divided into eight age groups; $12-13$ year, $14-15$ years, $16-17$ years, $18-19$ years, $20-21$ years, $22-23$ years, $24-25$ years, and $26-35$ years. The later part of the sampled age range was collapsed due to smaller numbers of subjects at each year over the age of 26 years.

Saliva was available for all 397 subjects at first sampling, but fewer had data for the second (1\% missing) and third (11\% missing) samples obtained on the same day. The current consensus in addressing missing data favors multiple imputation (MI), which avoids problems inherent in mean substitution and exclusion of cases with missing data (30). Further, MI retains the error variance lost from regression-based single imputation approaches. For the present data set, missing value analysis was first conducted using PASW to examine the pattern of missing values for cortisol at the second and third samples, then MI was conducted with PASW, using fully conditional specification (31). The results of the analyses with imputed data are presented below. (When the analyses were conducted without imputation, the same pattern of results was obtained.) 


\section{RESULTS}

\section{Participant Characteristics}

Consistent with the demographics presented in the recently published overview of the project (27), the CHR and control groups did not differ on age $(t(1,396)=.19, \mathrm{p}=.86)$, sex $\left(X^{2}(1)=.007, p=.973\right)$ or ethnicity $\left(X^{2}(9)=7.1, p=.63\right)$. The demographic characteristics of the sample are shown in Table 1.

\section{ANALYSES OF CORTISOL DATA}

Analyses showed significant correlations among the 3 salivary cortisol samples; samples 1 $\& 2, \mathrm{r}=.74, \mathrm{p}<.001$, samples $2 \& 3, \mathrm{r}=.76, \mathrm{p}<.001$, and samples $1 \& 3, \mathrm{r}=.62, \mathrm{p}<.001$, indicating reliability of the assay. Mean cortisol across the 3 samples was derived for each subject.

Preliminary analyses were conducted to identify correlates of cortisol for inclusion as covariates in analyses of diagnostic group differences. Because some prodromal subjects were on psychotropic and other medications when they entered the study, analyses were also conducted to examine the relation of medication with cortisol. These analyses revealed no significant relation of mean cortisol with antipsychotics ( $\mathrm{p}=.53)$, antidepressants $(\mathrm{p}=.99)$, stimulants ( $\mathrm{p}=.50)$, or mood stabilizers $(\mathrm{p}=.12)$ in the prodromal group, and no relation with birth control medication in the females $(\mathrm{p}=.43)$.

As expected, correlational analyses revealed a significant inverse relation between time of onset of saliva sampling and mean cortisol, $\mathrm{r}=-.12, \mathrm{p}<.01$. This reflects the normal diurnal decline in morning cortisol. Thus sampling time was included as a covariate in subsequent analyses. T-tests revealed no significant relation between cortisol and alcohol, dairy, or caffeine consumption, subsequent to $7 \mathrm{pm}$ the night before saliva sampling. But those who reported tobacco use had higher cortisol values than nonusers $(t(1,396)=2.50, \mathrm{p}<.05)$.

Tobacco use was also included as a covariate in analyses.

ANCOVAs, with sampling time and tobacco use as covariates, revealed no significant differences in mean cortisol as a function of sex or ethnicity, but consistent with previous reports, there was a significant difference as a function of age group, with higher levels associated with increasing age, $F(7,387)=2.70, p<.01$.

Cortisol data were analyzed in a one-way (diagnostic group: CHR versus Control) ANCOVA, with age group, time at onset of saliva sampling and tobacco use as covariates. The results yielded a significant main effect for diagnostic group, $F(1,392)=5.05, p<.05$, with higher levels in the CHR group. (See Figure 1.)

\section{THE RELATION OF CORTISOL WITH BASELINE SYMPTOM SEVERITY}

Correlational analyses were conducted to examine the relation of cortisol with ratings of symptoms severity for the four prodromal symptom scales. Significant, modest, positive correlations with cortisol were obtained for the positive, $r=.13, p<.01$, negative, $r=.09, p<$. 05 , general, $\mathrm{r}=.11, \mathrm{p}<.05$, and disorganized symptom ratings, $\mathrm{r}=.11, \mathrm{p}<.05$. As described, among the general symptoms there are four items, including separate ratings of dysphoric mood and impaired stress tolerance. Because of the potential relevance of these individual items to cortisol levels, they were examined separately. The correlations between baseline cortisol and symptom ratings were significant for dysphoric $\operatorname{mood} r=.11, \mathrm{p}<.05$, and impaired stress tolerance, $r=.12, \mathrm{p}<.05$, but not sleep disturbance, $\mathrm{r}=.08, \mathrm{p}=.09$, or motor disturbances, $\mathrm{r}=.00, \mathrm{p}=49$. 


\section{SYMPTOM PROGRESSION}

At the time of this writing, follow-up assessments of CHR participants are ongoing, so the final conversion rate is not yet known. And, of those who have reached a psychotic level of severity on the SIPS, the DSM diagnosis has not yet been established for all. In the interim, in order to determine whether baseline cortisol is linked with symptom progression, preliminary analyses were conducted using data for those $136 \mathrm{CHR}$ subjects in the present sample who had been followed at least 24 months without manifesting psychotic symptoms $\underline{o r}$ had reached a psychotic level of symptom severity based on the SIPS. The exclusion of CHR subjects who were not yet followed 24 months and had not transitioned reduced the likelihood of including false negatives. The following categorization was used: remission $(n=43)$ (all positive symptoms are rated less than 3), symptomatic $(n=37)$ (one or more of positive symptoms in the previous 4 weeks were rated $3-5$, but with no increase in last year), prodromal progression $(\mathrm{n}=24)$ (continues to meet prodromal criteria with one or more positive symptom rated 3-5 and increasing in severity), or psychotic $(\mathrm{n}=32)$ (has increased to a rating of 6 on one or more positive symptoms).

Cortisol data were analyzed in a one-way (diagnostic group; controls, remission, symptomatic, prodromal progression, or psychotic) ANCOVA, with age, time at onset of saliva sampling, and tobacco use as covariates. There was a significant main effect for diagnostic group, $\mathrm{F}(4,346)=2.46$, $\mathrm{p}<.05$, with posthoc groups contrasts showing that $\mathrm{CHR}$ subjects in the psychotic group had significantly higher baseline cortisol than those in the control $(\mathrm{p}=.01)$ and remission $(\mathrm{p}=.03)$ groups. There were no other significant group differences. (See Figure 2.)

\section{DISCUSSION}

This study examined cortisol levels in healthy controls and subjects designated as CHR for psychosis. As previously reported, there was an age-related increase in cortisol through adolescence/young adulthood, for both diagnostic groups. Also, as predicted, the CHR group showed significantly higher cortisol levels than controls, and cortisol levels were correlated with ratings of symptom severity at baseline and with the progression of prodromal syndromes.

The finding of nonspecific and modest relations between symptom severity and cortisol levels is consistent with several previous reports (8-10). The small magnitude of the correlations may partially reflect the restricted range of symptom severity ratings ( 0 to 5 ) utilized by the SIPS and similar measures for the prodromal range, with a rating of 6 being at the psychotic level of severity and rarely occurring at baseline. Also relevant to consider is that the correlations are based on cross-sectional data and may be diminished by individual differences in sensitivity to the effects of glucocorticoids on brain and behavior. Thus the relations might be more pronounced in within-subjects designs where the covariance between cortisol and symptoms is measured longitudinally.

Though preliminary, the analyses of the interim outcome data suggest that baseline cortisol is linked with the progression of the prodrome; those who transition to the level of 6 or higher on one or more of the SIPs positive symptoms showing the highest cortisol level. Of course, the CHR group has only been followed to a maximum of two years, and it has been shown that there are a substantial number of transitions to psychosis that occur beyond the second year after prodrome ascertainment. It should therefore be assumed that there are false negatives in this interim outcome measure. When the entire NAPLS CHR sample is recruited and the follow-up diagnostic assessments completed, we will conduct analyses that include specific DSM diagnostic outcomes, 
The current and similar previous findings raise questions about the relation between heightened HPA activity and risk for psychosis. Is heightened cortisol the consequence of developing clinical risk symptoms or does it play a role in triggering or exacerbating symptoms? The symptoms of the CHR syndromes are often subjectively stressful, and it is plausible that this distress activates the HPA axis. Alternatively, as implied in diathesisstress models, the causal relation may be in the opposite direction, such that biological stress systems trigger the expression of symptoms in some CHR individuals.

There are a variety of potential neural mechanisms through which heightened cortisol secretion might trigger or exacerbate psychotic symptoms, as well as the cognitive deficits that often accompany them (32). Animal and human research has shown that HPA activation can augment dopamine activity (33-38). In nonhuman primates, stress-induced cortisol levels are associated with higher binding of a dopamine agonist to striatal D2/D3 receptors as measured by PET (36). Similar results have been reported with CHR and normal human subjects, such that cortisol levels are correlated with amphetamine-induced DA release in the striatum (37-38). These findings suggest that HPA activity may be linked with psychosis via transient effects on DA. Consistent with this interpretation, daily, repeated measurement of cortisol and symptoms showed that first-degree relatives of psychotic patients manifested increases in psychotic experiences in conjunction with increased cortisol (8).

It is also possible that genomic mechanisms are mediating effects of HPA activity on vulnerability to psychotic symptoms via intracellular receptors (39-46). Genomic mechanisms, via nuclear receptors, can regulate gene expression and modulate brain development. There is extensive evidence from experimental animal research that steroid hormones affect brain organization during adolescence (41), and recent data indicate similar effects in humans $(42,43)$. Several recent studies of human subjects also show an inverse relation of baseline cortisol with cortical gray matter and hippocampal volume $(44,45)$. As noted above, the prodrome is associated with brain changes, including reduced gray matter volume, beyond that observed in healthy controls (15-18). Cortisol levels outside the normative range may be altering gene expression and contributing to these more pronounced volumetric declines via modulation of BDNF and other aspects of neurogenesis (47-50). Alternatively, some CHR subjects may have vulnerability genes that are being triggered by heightened cortisol. Finally, genes involved in cortisol metabolism may be among the risk genes for psychotic disorders (5).

In addition to the issue of the relation between cortisol and brain abnormalities, the complex interplay between cortisol levels and receptor characteristics is relevant. There is a dynamic relation of cortisol activity with glucocorticoid (GC) and mineralocorticoid (MR) receptors and with the genes that govern their expression (51-53). The effect of cortisol on brain and behavior would be expected to vary as a function of receptor characteristics. Thus, measurement of receptors, when combined with measures of cortisol, may yield a more complete picture of the role of the HPA axis in psychosis. To date, the few studies of receptors in psychotic disorders indicate reductions in brain GR mRNA (54-55), and MR mRNA expression (56).

The primary limitation of the present, and most other studies of CHR subjects, is the absence of control over psychotropic medications. A subgroup of the present sample was on a psychotropic medication, and the protocol did not require medication withdrawal. Although we found no relation between psychotropics and cortisol, as described above, previous longitudinal studies have revealed that atypical antipsychotics reduce cortisol levels $(1,57)$. If pre-baseline symptom severity was a precipitant of antipsychotic prescription in the present sample, as would be expected, the result may have been a reduction in baseline cortisol levels and symptoms for the medicated subgroup. In other words, medicated 
participants may have had higher pre-baseline cortisol levels and symptoms that were lowered with medication, thereby attenuating the difference between the medicated and nonmedicated CHR participants. This possibility can be examined in subsequent studies of this sample, as medication changes are monitored longitudinally in conjunction with cortisol.

As noted above, this is an ongoing study and follow-ups are not complete, thus we do not know the eventual rate of psychosis or the optimal set of predictors of conversion. Nonetheless, the present sample exceeds that of most CHR studies, and the second half of the sample will provide opportunities for replication. These studies will address questions concerning the relation of cortisol with other biomarkers, symptom progression, and diagnostic outcome, as well as heterogeneity among CHR converters in these relations. With respect the latter, it is of interest to determine whether hypersecretion of cortisol characterizes an etiological subgroup.

\section{Acknowledgments}

Sources of grant and financial support: This research was supported by NIMH Grants U01MH081988 (to E. Walker), U01MHMH081988 (to J. Addington), U01MHMH081988 (to B Cornblatt), U01MHMH081988, R01 MH 60720, U01 MH08022, K24 MH76191 (to K. Cadenhead), U01 MH081902 (to T. Cannon), U01MHMH081988 (to D. Perkins), U01MHMH081988 (to L. Seidman), U01MHMH081988, U01 MH82022 (to S. Woods), 1-R21MH083138-1, 1R01-MH092512, 5R2-R21-MH079189, 1-R21-MH068513 and the Emory Neuroscience Initiative Grant (to B.D. Pearce), and UR01 MH081944 (to M. Tsuang). We thank Christina L. Harwell, William Wilson and Sandeep Pathi for technical assistance.

\section{References}

1. Walker E, Mittal V, Tessner K. Stress and the hypothalamic pituitary adrenal axis in the developmental course of schizophrenia. Annu Rev Clin Psycho. 2008; 4:189-216.

2. Holtzman CW, Trotman HD, Goulding SM, Ryan AT, McDonald AN, Shapiro DI, Brasfield JL, Walker EF. Stress and Neurodevelopmental Processes in the Emergence of Psychosis. Neuroscience. 2013 In Press.

3. Mondelli V, Dazzan P, Hepgul N, Di Forti M, Aas M, D’Albenzio A, et al. Abnormal cortisol levels during the day and cortisol awakening response in first-episode psychosis: the role of stress and of antipsychotic treatment. Schizophrenia research. 2010; 116(2):234-242. [PubMed: 19751968]

4. Guest PC, Schwarz E, Krishnamurthy D, Harris LW, Leweke FM, Rothermundt M, et al. Altered levels of circulating insulin and other neuroendocrine hormones associated with the onset of schizophrenia. Psychoneuroendocrinology. 2011; 36(7):1092-1096. [PubMed: 21251762]

5. Steen NE, Tesli M, Kahler AK, Methlie P, Hope S, Barrett EA, et al. SRD5A2 is associated with increased cortisol metabolism in schizophrenia spectrum disorders. Prog Neuropsychopharmacol Biol Psychiatry. 2010; 34(8):1500-1506. [PubMed: 20800085]

6. Stetler C, Miller GE. Depression and hypothalamic-pituitary-adrenal activation: a quantitative summary of four decades of research. Psychosom Med. 2011; 73(2):114-126. [PubMed: 21257974]

7. Yildirim O, Dogan O, Semiz M, Kilicli F. Serum cortisol and dehydroepiandrosterone-sulfate levels in schizophrenic patients and their first-degree relatives. Psychiatry Clin Neurosci 2011. 2011; 65(6):584-591.

8. Collip D, Nicolson NA, Lardinois M, Lataster T, Van Os J, Myin-Germeys I. Daily cortisol, stress reactivity and psychotic experiences in individuals at above average genetic risk for psychosis. Psychol Med. 2011; 41(11):2305-2315. [PubMed: 21733219]

9. Garner B, Phassouliotis C, Phillips LJ, Markulev C, Butselaar F, Bendall S, Yun Y, McGorry PD. Cortisol and dehydroepiandrosterone-sulphate levels correlate with symptom severity in firstepisode psychosis. J Psychiatr Res. 2011; 45(2):249-255. [PubMed: 20619421]

10. Belvederi Murri M, Pariante CM, Dazzan P, Hepgul N, Papadopoulos AS, Zunszain P, et al. Hypothalamic-pituitary-adrenal axis and clinical symptoms in first-episode psychosis.

Psychoneuroendocrinology. 2012; 37(5):629-644. [PubMed: 21930345] 
11. Miller TJ, McGlashan TM, Rosen JL, Cadenhead K, Ventura J, McFarlane W, et al. Prodromal assessment with the Structured Interview for Prodromal Syndromes and the Scale of Prodromal Symptoms: Predictive validity, inter-rater reliability, and training to reliability. Schizophrenia Bulletin. 2003; 29:703-715. [PubMed: 14989408]

12. Olsen KA, Rosenbaum B. Prospective investigations of the prodromal state of schizophrenia: assessment instruments. Acta Psychiat Scand. 2006; 113(4):273-282. [PubMed: 16638071]

13. Cannon TD, Cadenhead K, Cornblatt B, Woods SW, Addington J, Walker E, et al. Prediction of psychosis in youth at clinical high risk: a multisite longitudinal study in North America. Arch Gen Psychiatry. 2008; 65:28-37. [PubMed: 18180426]

14. Ruhrmann S, Schultze-Lutter F, Salokangas RKR, Heinimaa M, Linszen D, Dingemans P, et al. Prediction of psychosis in adolescents and young adults at high risk: Results from the Prospective European Prediction of Psychosis study. Arch Gen Psychiatry. 2010; 67(3):241-251. [PubMed: 20194824]

15. Gothelf D, Hoeft F, Ueno T, Sugiura L, Lee AD, Thompson P, Reiss AL. Developmental changes in multivariate neuroanatomical patterns that predict risk for psychosis in 22q11.2 deletion syndrome. J Psychiatr Res. 2011; 45(3):322-331. [PubMed: 20817203]

16. Jacobson S, Kelleher I, Harley M, Murtagh A, Clarke M, Blanchard M, et al. Structural and functional brain correlates of subclinical psychotic symptoms in 11-13 year old schoolchildren. Neuroimage. 2010; 49(2):1875-1885. [PubMed: 19770054]

17. Jung WH, Kim JS, Jang JH, Choi JS, Jung MH, Park JY, et al. Cortical thickness reduction in individuals at ultra-high-risk for psychosis. Schizophr Bull. 2011; 37(4):839-849. [PubMed: 20026559]

18. Witthaus H, Brune M, Kaufmann C, Bohner G, Ozgurdal S, Gudlowski Y, et al. White matter abnormalities in subjects at ultra-high-risk for schizophrenia and first-episode schizophrenic patients. Schizophr Res. 2008; 102(1-3):141-149. [PubMed: 18515047]

19. Aiello G, Horowitz M, Hepgul N, Pariante CM, Mondelli V. Stress abnormalities in individuals at risk for psychosis: A review of studies in subjects with familial risk or with "at risk" mental state. Psychoneuroendocrinology. 2012; 37(10):1600-1613. [PubMed: 22663896]

20. Garner B, Pariante CM, Wood SJ, Velakoulis D, Phillips L, Soulsby B, et al. Pituitary volume predicts future transition to psychosis in individuals at ultra-high risk of developing psychosis. Biol Psychiat. 2005; 58:417-423. [PubMed: 16026767]

21. Thompson KN, Phillips LJ, Komesoroff HP, Yuen S, Yuen HP, Wood SJ, et al. Stress and HPAaxis functioning in young people at ultra high risk for psychosis. J Psychiatric Res. 2007; 41:561569.

22. Thompson KN, Berger G, Phillips LJ, Komesaroff P, Purcell R, McGorry PD. HPA axis functioning associated with transition to psychosis: Combined DEX/CRH test. J Psychiatr Res. 2007; 41:446-450. [PubMed: 16403528]

23. Weinstein DD, Donald D, Schiffman J, Walker E, Bonsall R. Minor physical anomalies, dermatoglyphic abnormalities and cortisol secretion in adolescents with schizotypal personality disorder. Am J Psychiatry. 1999; 156:617-623. [PubMed: 10200743]

24. Walker EF, Brennan PA, Esterberg M, Brasfield J, Pearce B, Compton MT. Longitudinal changes in cortisol secretion and conversion to psychosis in at-risk youth. J Abnorm Psychol. 2010; 119(2): 401-408. [PubMed: 20455612]

25. Mizrahi R, Addington J, Rusjan PM, Suridjan I, Ng A, Boileau I, et al. Increased stress-induced dopamine release in psychosis. Biol Psychiatry. 2012; 71(6):561-567. [PubMed: 22133268]

26. Mondelli V, Cattaneo A, Belvederi MM, Di Forti M, Handley R, Hepgul N, et al. Stress and inflammation reduce brain-derived neurotrophic factor expression in first-episode psychosis: a pathway to smaller hippocampal volume. The Journal of clinical psychiatry. 2011; 72(12):16771684. [PubMed: 21672499]

27. Addington J, Cadenhead K, Cornblatt B, Mathalon D, McGlashan T, Perkins D, et al. North American Prodrome Longitudinal Study (NAPLS 2): Overview and Recruitment. Schizophrenia Research. 2012 In press. 
28. First, MB.; Spitzer, RL.; Gibbon, M.; Williams, JBW. Structured Clinical Interview for DSM-IVTR Axis I Disorders, Research Version, Non-patient Edition. (SCID-I/NP). New York: Biometrics Research, New York State Psychiatric Institute; 2002.

29. Li I, Chiou HH, Shen PS. Correlations between cortisol level and internalizing disposition of young children are increased by selecting optimal sampling times and aggregating data. Dev Psychobiol. 2007; 49:633-639. [PubMed: 17680610]

30. Graham JW. Missing Data Analysis: Making It Work in the Real World. Annual Review of Psychology. 2009; 60:549-576.

31. Van Buuren S. Multiple imputation of discrete and continuous data by fully conditional specification. Stat Methods Med Res. 2007; 16:219-242. [PubMed: 17621469]

32. Gomez RG, Posener JA, Keller J, DeBattista C, Solvason B, Schatzberg AF, et al. Effects of major depression diagnosis and cortisol levels on indices of neurocognitive function. Psychoneuroendocrinology. 2009; 34:1012-1018. [PubMed: 19261389]

33. Van Craenenbroeck K, De Bosscher K, Vanden Berghe W, Vanhoenacker P, Haegeman G. Role of glucocorticoids in dopamine-related neuropsychiatric disorders. Mol Cell Endocrinol. 2005; 245(1-2):10-22. [PubMed: 16310935]

34. Schatzberg AF, Rothschild AJ, Langlais PJ, Bird ED, Cole JO. A corticosteroid/dopamine hypothesis for psychotic depression and related states. Journal of Psychiatric Research. 1985; 19(1):57-64. [PubMed: 2859366]

35. Keller J, Flores B, Gomez RG, Solvason HB, Kenna H, Williams GH, Schatzberg AF. Cortisol circadian rhythm alterations in psychotic major depression. Biological psychiatry. 2006; 60:275. [PubMed: 16458262]

36. Tsukada H, Ohba H, Nishiyama S, Kakiuchi T. Differential effects of stress on [11C]raclopride and [11C]MNPA binding to striatal D2/D3 dopamine receptors: a PET study in conscious monkeys. Synapse. 2011; 65(1):84-89. [PubMed: 20687105]

37. Pruessner JC, Dedovic K, Pruessner M, Lord C, Buss C, Collins L, Dagher A, Lupien SJ. Stress regulation in the central nervous system: evidence from structural and functional neuroimaging studies in human populations. Psychoneuroendocrinology. 2010; 35(1):179-791. [PubMed: 19362426]

38. Wand GS, Oswald LM, McCaul ME, Wong DF, Johnson E, Zhou Y, Kuwabara H, Kumar A. Association of amphetamine-induced striatal dopamine release and cortisol responses to psychological stress. Neuropsychopharmacology. 2007; 32(11):2310-2320. [PubMed: 17342167]

39. Mayer JL, Klumpers L, Maslam S, De Kloet ER, Joels M, Lucassen PJ. Brief Treatment With the Glucocorticoid Receptor Antagonist Mifepristone Normalises the Corticosterone-Induced Reduction of Adult Hippocampal Neurogenesis. Journal of neuroendocrinology. 2006; 18:629_ 631. [PubMed: 16867184]

40. Melcangi RC, Panzica G, Garcia-Segura LM. Neuroactive steroids: focus on human brain. Neuroscience. 2011; 191:1-5. [PubMed: 21704130]

41. Vigil P, Orellana RF, Cortes ME, Molina CT. Endocrine Modulation of the Adolescent Brain: A Review. J Pediatr Adolesc Gynecol. 2011; 24 (6):330-337. [PubMed: 21514192]

42. Peper JS, Hulshoff Pol HE, Crone EA, van Honk J. Sex steroids and brain structure in pubertal boys and girls: a mini-review of neuroimaging studies. Neuroscience. 2011; 191:28-37. [PubMed: 21335066]

43. Herting MM, Maxwell EC, Irvine C. The Impact of Sex, Puberty, and Hormones on White Matter Microstructure in Adolescents. Cereb Cortex. 2012; 22:1979-1992. [PubMed: 22002939]

44. Mondelli V, Pariante CM, Navari S, Aas M, D’ Albenzio A, Di Forti M, et al. Higher cortisol levels are associated with smaller left hippocampal volume in first-episode psychosis. Schizophr Res. 2010; 119(1-3):75-78. [PubMed: 20071148]

45. Tessner KD, Walker EF, Dhruv SH, Hochman K, Hamann S. The relation of cortisol levels with hippocampus volumes under baseline and challenge conditions. Brain Res. 2007; 1179:70-78. [PubMed: 17936736]

46. Castro-Fornieles J, Bargallo N, Lazaro L, Andres S, Falcon C, Plana MT, Junque C. A crosssectional and follow-up voxel-based morphometric MRI study in adolescent anorexia nervosa. J Psychiatr Res. 2009; 43(3):331-340. [PubMed: 18486147] 
47. Bennett AO. Stress and anxiety in schizophrenia and depression: glucocorticoids, corticotropinreleasing hormone and synapse regression. Aust N Z J Psychiatry. 2008; 42(12):995-1002. [PubMed: 19016087]

48. Asato MR, Terwilliger R, Woo J, Luna B. White Matter Development in Adolescence: A DTI StudyCereb. Cortex. 2010; 20 (9):2122-2131.

49. Issa G, Wilson C, Terry AV Jr, Pillai A. An inverse relationship between cortisol and BDNF levels in schizophrenia: data from human postmortem and animal studies. Neurobiol Dis. 2010; 38(3): 327-333. [PubMed: 20347983]

50. Miodownik C, Maayan R, Ratner Y, Lerner V, Pintov L, Mar M, Weizman A, Ritsner MS. Serum levels of brain-derived neurotrophic factor and cortisol to sulfate of dehydroepiandrosterone molar ratio associated with clinical response to L-theanine as augmentation of antipsychotic therapy in schizophrenia and schizoaffective disorder patients. Clin Neuropharmacol. 2011; 34(4):155-60. [PubMed: 21617527]

51. Lee MS, Choi HS, Kwon SH, Morita K, Her S. Identification of the functional domain of glutocorticoid receptor involved in RU486 antagonism. J Steroid Biochem Mol Biol. 2009; 117(13):67-73. [PubMed: 19635558]

52. Sinclair D, Webster MJ, Wong J, Weickert CS. Dynamic molecular and anatomical changes in the glucocorticoid receptor in human cortical development. Mol Psychiatry. 2011; 16(5):504-515. [PubMed: 20308989]

53. Howell MP, Muglia LJ. Effects of genetically altered brain glucocorticoid receptor action on behavior and adrenal axis regulation in mice. Front Neuroendocrinol. 2006; 27(3):275-284. [PubMed: 16814372]

54. Perlman WR, Webster MJ, Kleinman JE, Weickert CS. Reduced glucocorticoid and estrogen receptor alpha messenger ribonucleic acid levels in the amygdala of patients with major mental illness. Biol Psychiatry. 2004; 56(11):844-852. [PubMed: 15576061]

55. Webster MJ, Knable MB, O’Grady J, Orthmann J, Weickert CS. Regional specificity of brain glucocorticoid receptor mRNA alterations in subjects with schizophrenia and mood disorders. Mol Psychiatry. 2002; 7(9):985-94. 924Re. [PubMed: 12399952]

56. Xing GQ, Russell S, Webster MJ, Post RM. Decreased expression of mineralocorticoid receptor mRNA in the prefrontal cortex in schizophrenia and bipolar disorder. Int $\mathrm{J}$ Neuropsychopharmacology. 2004; 7(2):143-153.

57. Bicikova M, Hampl R, Hill M, Ripova D, Mohr P, Putz Z. Neuro- and immunomodulatory steroids and other biochemical markers in drug-naïve schizophrenia patients and the effect of treatment with atypical antipsychotics. Neuroendocrinology Letters. 2011; 32(2):141-147. [PubMed: 21552193] 


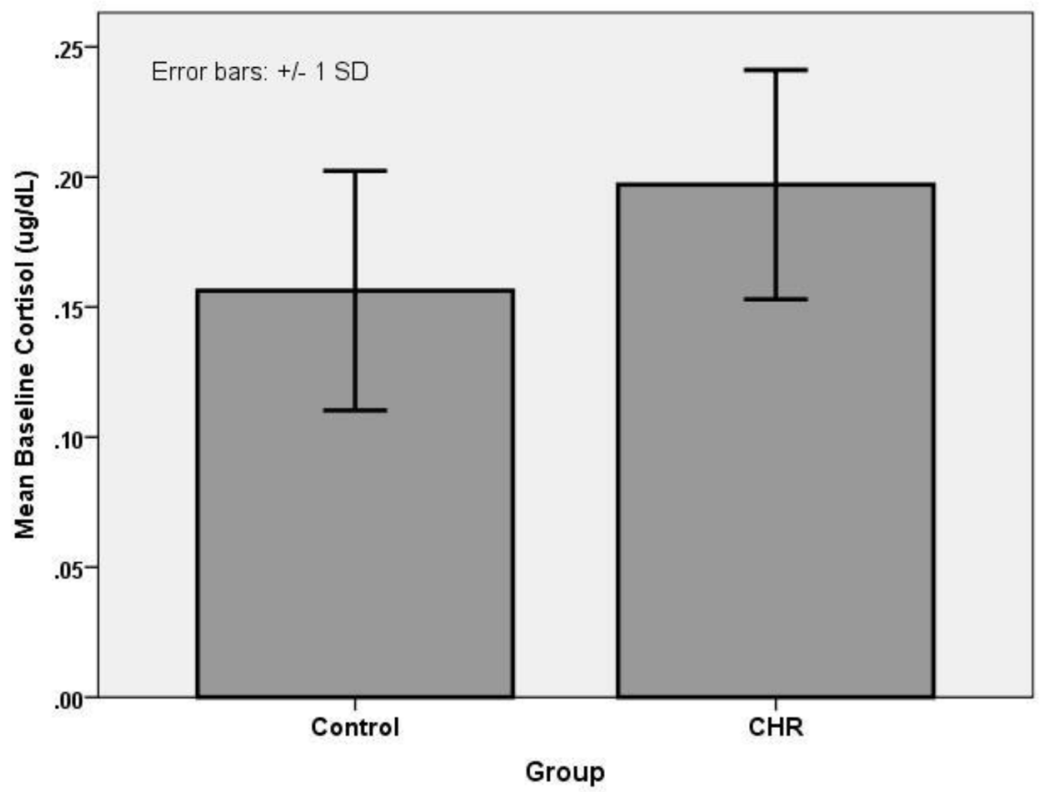

Figure 1.

Mean Cortisol Levels For CHR and Healthy Control Groups. 


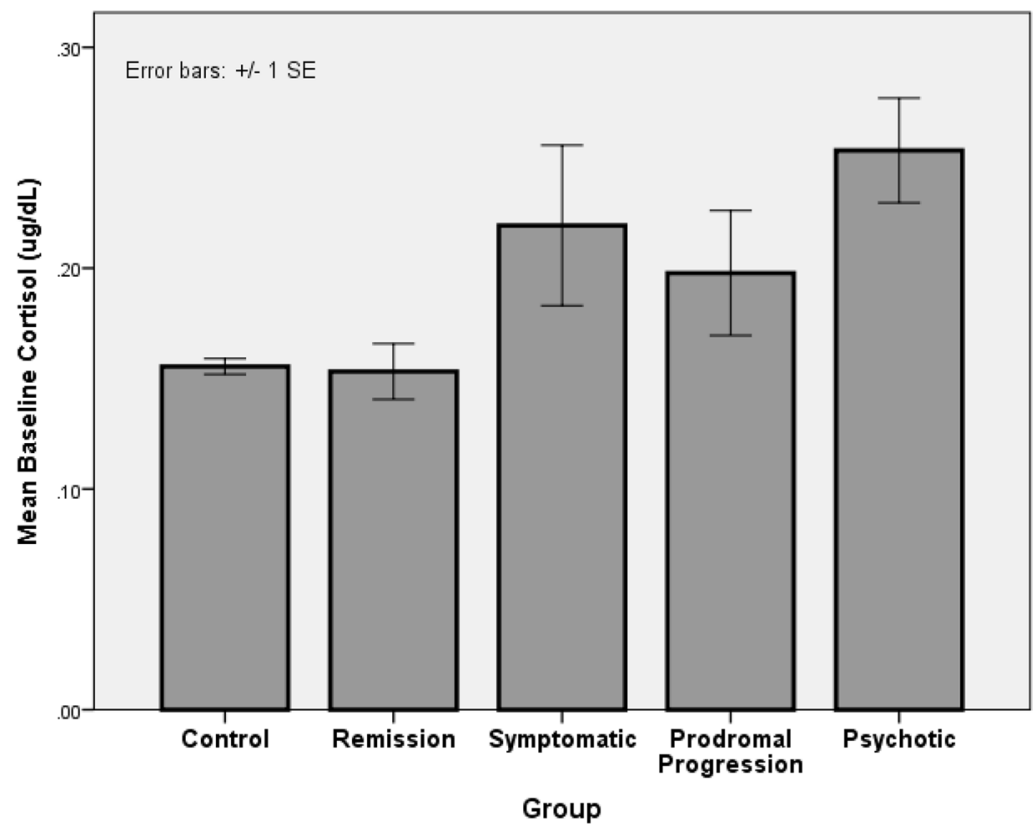

Figure 2.

Mean Cortisol Levels by Diagnostic Outcome Group 
Table 1

Demographic and Clinical Characteristics

\begin{tabular}{lcc}
\hline & Healthy Controls & Clinical High Risk (CHR) \\
Number of Participants (N=397) & 141 & 256 \\
Age, years (SD) & $19.1(4.6)$ & $19(4.2)$ \\
Sex, male/female & $76 / 65$ & $146 / 110$ \\
Education, years (SD) & $12.17(3.52)$ & $11.72(2.64)$ \\
Current Psychotropic medication, $\%$ & $0 \%$ & $25 \%$ \\
Race/ethnicity (\%) & & \\
First Nations & $2 \%$ & $2 \%$ \\
East Asian & $4 \%$ & $2 \%$ \\
Southeast Asian & $2 \%$ & $3 \%$ \\
South Asian & $2 \%$ & $14 \%$ \\
Black & $15 \%$ & $6 \%$ \\
Central/South American & $4 \%$ & $1 \%$ \\
West/Central Asia and Middle East & $1 \%$ & $54 \%$ \\
White & $58 \%$ & $1 \%$ \\
Native Hawaiian or Pacific Islander & $1 \%$ & \\
Interracial & $11 \%$ & $2 \%$ \\
\hline
\end{tabular}

